\title{
The role of contingencies in the control of behavior
}

DIANE D. EDWARDS, JACK R. WEST, VIRGINIA JACKSON UNIVERSITY OF MISSOURI AT KANSAS CITY

A systematic replication of Herrnstein's (1966) procedure demonstrated that non-contingent consequation is not sufficient to maintain a previously stable response rate acquired and maintained by either a Fl $11 \mathrm{sec}$ or a Fl $60 \mathrm{sec}$ contingency. The temporal relationship between a response and its consequences appears to be a crucial variable in the maintenance of behavior.

In 1948, Skinner reported that if grain is delivered independently of designated responses to pigeons at $75 \%$ body weight, these pigeons will develop individual behaviors presumably as a function of accidental correlations between movements of the organism and subsequent events (grain). Some birds were observed to turn in circles, some to bob their heads, and some to move from one foot to another at high rates. Since none of these responses was defined by the experimenter via the experimental program, and yet occurred consistently, explanations were made in accord with the laws of contingent consequences. Since each bird was undoubtedly behaving when the grain was delivered, what each bird was doing was increased in probability. This increase in behavior increased the probability that the next delivery of grain would follow the same behavior. "This strengthens the response still further and subsequent reinforcement becomes more probable. It is true that some responses go unreinforced and some reinforcements appear when the response has not yet been made, but the net result is the development of a considerable state of strength"' (Skinner, 1948, p. 168).

In a recent review by Herrnstein (1966), a study was reported in which a pigeon was trained to peck an illuminated disc for food on a fixed-interval 11 sec schedule. After nine sessions, the pigeon was presented food every 11 sec regardless of its behavior. After 21 sessions of the noncontingent programming of food, the fixed-interval contingency was reinstated. A final phase of the experiment involved discontinuing the food presentation entirely (extinction). The data presented by Herrnstein indicated differences in the rate of response as a function of contingent versus noncontingent programming of accelerating consequences. In discussing the role of contingent and noncontingent consequences, Herrnstein suggests that an observer watching experimental animals might find it difficult to distinguish between an animal that was explicitly trained to perform a particular behavior and one whose behavior only accidentally occurred while food was being presented. He suggests that a high probability behavior (one that was systematically trained during the fixedinterval contingency) will not reflect the differences between contingent and noncontingent arrangements of consequences. Because of the apparent discrepancy between what the data say and what is said about the data, a systematic replication of the Herrnstein study was performed.

Subjects

Eight Sprague-Dawley rats and two homing pigeons were maintained at $80 \%$ of their ad lib weights throughout the experiment.

Apparaius

A Lehigh Valley Model 1316 two bar rat box and a Grason-Stadler two key pigeon box served as the experimental chambers. A $16 \%$ sucrose solution in the amount of $.08 \mathrm{cc}$ served as a consequence for rats and pigeon grain delivered for $2 \mathrm{sec}$ durations followed key pecks of the pigeons. Relay circuitry and cumulative recordings were provided by Lehigh Vally, Grason-Stadler, and Scientific Prototype Electronic companies.

\section{Procedure}

Four rats and one bird were shaped and maintained on a fixed-interval $11 \mathrm{sec}$ schedule until their response rates reached a stability criterion of $5 \%$ (Schoenfeld, Cummings, \& Hearst, 1956). Another four rats and the other pigeon were shaped and maintained on a fixed-interval $60 \mathrm{sec}$ schedule until response rates stabilized at $5 \%$. Once stability was achieved, the sucrose or grain was delivered either every $11 \mathrm{sec}$ or every $60 \mathrm{sec}$ regardless of whether a bar press or a key peck occurred. Again stability was obtained using a 5\% criterion. At this point, the fixed-interval schedules were reinstated and stability obtained. The last manipulation involved the programming of extinction (neither bar press nor key peck produced sucrose or grain).

Results

Figure 1 presents responses per second across all manipulations under the FI 11 sec contingency. During the first 10 sessions, rate stabilized at about 0.22 responses/sec, while the FI 11 sec contingency was in effect. When sucrose was presented independent of behavior, response rate dropped to a median of 0.01 responses/sec. Reintroduction of the contingency produced acceleration in rate from near zero to a median of 0.10 responses/sec. When sucrose or grain was removed the behavior decelerated 


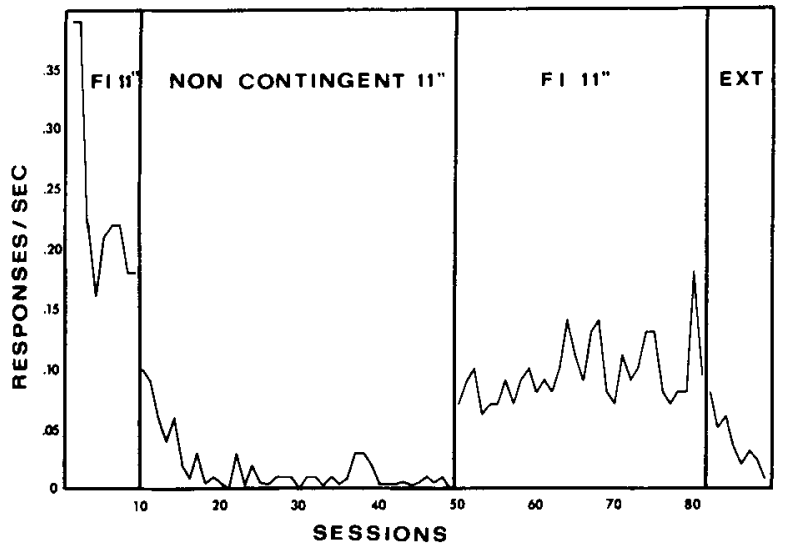

Fig. 1. Responses per sec across experimental manipulations of Fl $11 \mathrm{sec}$, non-contingent consequation, Fl $11 \mathrm{sec}$ contingent, and extinction for one rat.

to zero by the seventh day. Figure 1 is characteristic of all organisms under a FI $11 \mathrm{sec}$ contingency.

Figure 2 presents a similar comparison when a FI $60 \mathrm{sec}$ was programmed as the contingency. Rate stabilized at about 0.40 responses/sec. When the sucrose was programmed independent of behavior, rates decelerated to a median of 0.14 response/sec. Reintroduction of the contingency produced accelerated rates of 0.30 responses/sec while extinction produced a deceleration to near zero responses/sec in six days.

Discussion

The data presented in the present study are in agreement with those presented by Herrnstein (1966). However, the conclusions to be drawn from the data suggest that the high probability behavior acquired and maintained when consequences were contingent upon fixed intervals of $11 \mathrm{sec}$ or $60 \mathrm{sec}$ was not sufficiently

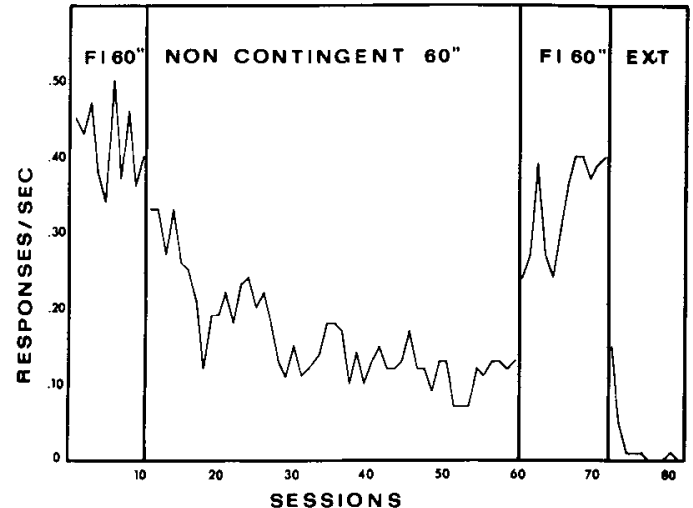

Fig. 2. Responses per sec across experimental manipulations of F1 $60 \mathrm{sec}$, non-contingent consequation, Fl $60 \mathrm{sec}$ contingent, and extinction for one rat.

maintained when noncontingent consequences were programmed. Both procedures of noncontingent consequation and extinction produced deceleration in rates.

Since these rate differences were observed in all Ss and under conditions of stable response rates, the exact temporal relationship between behavior and consequences must be systematically explored. These data suggest that the exact specification of a response and its consequence is necessary to both the acquisition and maintenance of behavior.

References

HERRNSTEIN, R. J. Superstition: a corollary of the principles of operant conditioning. In W. K. Honig, (Ed.) Operant Behavior New York: Appleton-Century-Crofts, 1966, pp. 33-51.

SCHOENFELD, W. N., CUMMINGS, W. W., \& HEARST, E. On the classification of reinforcement schedules. Proc. Nat. Acad.. Sci, $1956,42,563-570$.

SKINNER, B. F. "Superstition" in the pigeon. J. exp. Psychol, $1948,38, \quad 168.172$. 